\title{
Modeling of downward longwave radiation and radiative cooling potential in China $\odot$
}

Cite as: J. Renewable Sustainable Energy 11, 066501 (2019); https://doi.org/10.1063/1.5117319 Submitted: 01 July 2019 . Accepted: 10 October 2019. Published Online: 05 November 2019

Kai Chang, and Qingyuan Zhang

\section{COLLECTIONS}

F This paper was selected as Featured
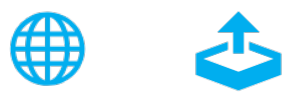

\section{AIP Author Services English Language Editing}




\title{
Modeling of downward longwave radiation and radiative cooling potential in China ${ }^{\circ}$ (c)
}

\author{
Cite as: J. Renewable Sustainable Energy 11, 066501 (2019); doi: 10.1063/1.5117319 \\ Submitted: 1 July 2019 . Accepted: 10 October 2019 . \\ Published Online: 5 November 2019

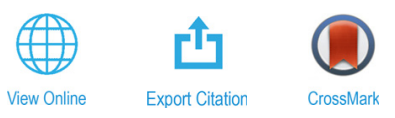

\author{
Kai Chang ${ }^{\text {a) }}$ and Qingyuan Zhang
}

\author{
AFFILIATIONS \\ Yokohama National University, Institute of Urban Innovation, Yokohama, Japan \\ a) Author to whom correspondence should be addressed: changkainenu@163.com
}

\begin{abstract}
The information on downward longwave (LW) radiation is necessary for the design of the passive cooling system of buildings. Because the measured LW radiation data are not available in most locations, few studies have focused on the modeling of LW radiation in China. In this study, empirical models for estimating LW radiation were proposed under all-sky conditions based on the meteorological parameters such as the ambient dry-bulb temperature, water vapor pressure, and relative humidity, which can be classified into four cases: All day, nighttime, and daytimes with and without considering the cloud modification factor. The proposed models performed are well compared with the existing models. The LW radiation datasets for 351 locations of China were developed using the proposed model for all the day based on the typical meteorological year. Moreover, the distribution map of radiative cooling potential in July was created using the proposed model for the nighttime, which can provide a valuable reference for building cooling design.
\end{abstract}

Published under license by AIP Publishing. https://doi.org/10.1063/1.5117319

\section{INTRODUCTION}

Downward longwave (LW hereafter) radiation is a significant factor in energy balance on the Earth's surface, as well as in the design of building radiative cooling systems. ${ }^{1}$ The LW radiation is usually observed at very few stations, while the routine meteorological parameters such as temperature and relative humidity are easy to access; therefore, developing models to estimate LW radiation is necessary based on the available routine meteorological elements.

The LW radiation originates from gases present in the atmosphere such as water vapor, carbon dioxide, and ozone, among which the water vapor plays a major role. Moreover, $90 \%$ of the LW radiation at the ground level comes from the first 800-1600 m above the Earth's surface. ${ }^{2}$ Therefore, the water vapor pressure and the ambient temperature of the Earth's surface are closely related to LW radiation. In addition, the cloud and the relative humidity can also affect LW radiation. $^{3-5}$

Currently, there are three main methods to estimate the LW radiation. The first type is the empirical model, ${ }^{6}$ which established the relationship between the measured LW radiation and routine meteorological parameters such as the water vapor pressure and ambient temperature. The second type is the physical model, which is based on the atmospheric radiative transfer phenomena, such as the LOWTRAN ${ }^{7}$ and MODTRAN. ${ }^{8}$ However, the detailed profiles of atmospheric constituents utilized in the model are not often available. The last type is the remote sensing method, which can estimate the LW radiation on a large scale based on the retrieval of some meteorological parameters such as the Earth's surface temperature. ${ }^{9}$ However, the estimation accuracy for specific location needs to be improved.

The empirical models are widely used for estimating the LW radiation in the world. Brunt ${ }^{10}$ proposed a model based on the water vapor pressure under clear-sky conditions for California. Some models were established $^{11-14}$ subsequently just based on the ambient temperature and water vapor pressure for different locations. Then, other meteorological parameters such as dew point temperature and relative humidity were used for establishing LW radiation models. ${ }^{15-17}$ The empirical models mentioned above were only suitable for clear-sky conditions, while the existence of clouds could increase LW radiation. ${ }^{2}$ Moreover, for the design of building passive cooling systems, the data utilized should reflect the long-term change in LW radiation under all-sky conditions, especially for the nighttime. Therefore, it is also significant to develop empirical models for all-sky conditions. So far, very few models can be used for all-sky conditions, though Crawford and Duchon ${ }^{18}$ proposed a model under all-sky conditions by considering the cloud cover.

Few studies were conducted to estimate LW radiation for China since little measured LW radiation data were available. Wang et al. ${ }^{19}$ addressed the estimation of LW radiation using the remote sensing method with the Moderate resolution imaging spectroradiometer (MODIS) data for the Tibetan Plateau region, China, but no empirical 
model was proposed in this study. Zhang and $\mathrm{Yu}^{20}$ estimated the LW radiation in different locations to obtain the radiative cooling potential over China; however, the calculation results were not validated due to the lack of the measured LW radiation data. Therefore, it is necessary to develop the empirical models that can be utilized for meteorological and geographic conditions of China.

The primary objective of this study is to develop new empirical models of LW radiation based on the routine meteorological parameters for locations in China. To accomplish this objective, the following steps were carried out: (1) the empirical models were established between the LW radiation and the ambient temperature, water vapor pressure, and relative humidity under all-sky conditions, which can be classified into four cases: All day, nighttime, and daytimes with and without considering the cloud modification factor; (2) the proposed LW radiation models were validated using the measured LW radiation in four locations of China: Changbaishan, Haibei, Qinghai, and Yucheng; (3) the hourly LW radiation dataset was developed based on the typical meteorological year (TMY) dataset ${ }^{21}$ for 351 locations in China; (4) the distribution maps of the LW radiation and the radiative cooling potential were generated over China, which can provide a valuable reference for building cooling design.

\section{METHODOLOGY}

\section{A. Measured data}

Since the routine meteorological stations do not provide the LW radiation data in China, the LW radiation data in this study were obtained from the AsiaFlux Database. ${ }^{22}$ Then, the LW radiation (watts per meter square), solar radiation (watts per meter square), water vapor pressure (hectopascal), ambient temperature (Kelvin), and relative humidity (percentage) with 1-h intervals were selected from the AsiaFlux Database in four locations of China (Changbaishan, Haibei, Qinghai, and Yucheng, as shown in Fig. 1). The detailed geographic information of the four locations, as well as the time period of the measurement, is summarized in Table I. The measured data were divided into two parts according to its use: One was used for developing new LW radiation models; the other was used for validating the proposed models.

\section{B. Development of new models}

Because the measured LW radiation data are not available in the routine meteorological stations, empirical models of the LW radiation were established based on different meteorological parameters from previous studies, where ambient dry-bulb temperature and water vapor pressure were commonly used.

In this study, the correlation analysis was first conducted between the LW radiation and various meteorological parameters. The correlations between the LW radiation and the different meteorological parameters are shown in Figs. 2 and 3 (taking Yucheng as an example). It can be seen that the LW radiation has a strong correlation with the ratio of the water vapor pressure to the ambient temperature, which complies with the natural logarithm function. Based on the ideal gas state equation, the ratio of the water vapor pressure to the

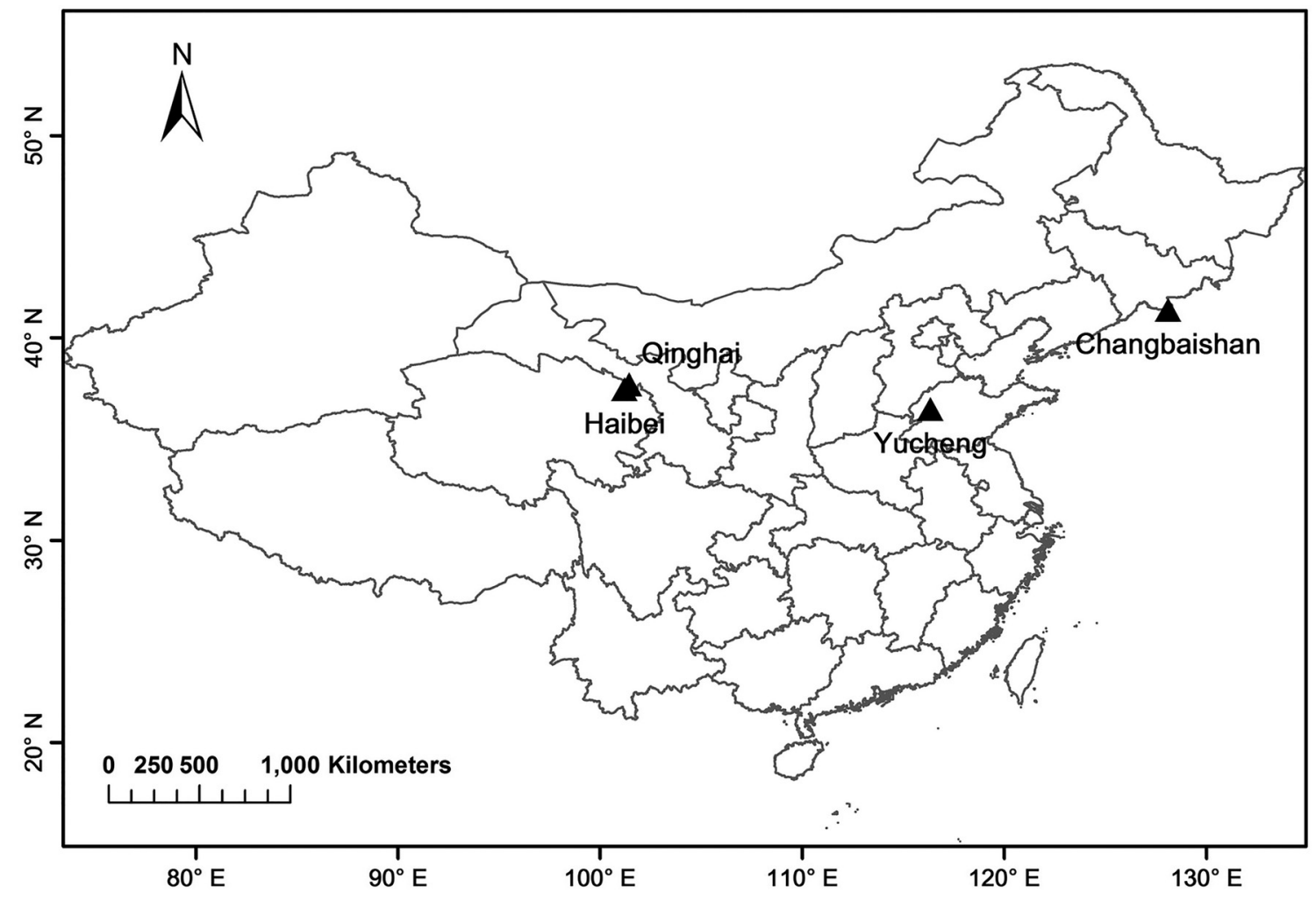

FIG. 1. Distribution of the four observation locations in China. 
TABLE I. Information related to the four observation locations.

\begin{tabular}{lccccc}
\hline \hline No. & Location & Latitude $\left({ }^{\circ} \mathrm{N}\right)$ & Longitude $\left({ }^{\circ} \mathrm{E}\right)$ & Elevation $(\mathrm{m} \mathrm{MSL})$ & Period-a $^{\mathrm{a}}$ \\
\hline 1 & Changbaishan & 41.40 & 128.10 & 736 & 2003,2004 \\
2 & Haibei & 37.48 & 101.20 & 3200 & 2004 \\
3 & Qinghai & 37.61 & 101.33 & 3250 & 2005 \\
4 & Yucheng & 36.50 & 116.34 & 28 & 2003 \\
\hline \hline
\end{tabular}

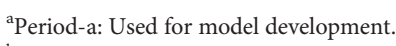

${ }^{\mathrm{b}}$ Period-b: Used for model validation.

ambient temperature can represent the water vapor density, and with the increase in that, the LW radiation will also increase. Moreover, the LW radiation also has a correlation with relative humidity. Therefore, the ambient dry-bulb temperature $\left(\mathrm{T}_{\mathrm{a}}\right)$, water vapor pressure $\left(\mathrm{e}_{\mathrm{a}}\right)$, and relative humidity (percentage) were employed in developing the new models as shown in Eq. (1).

The LW radiation during the daytime is necessary for the energy balance application, while that during the nighttime is more favorable for the building passive cooling system. ${ }^{3}$ Therefore, the empirical coefficients in Eq. (1) were calculated through regression analysis for the all day, nighttime, and daytime.

$$
R_{\downarrow}=\sigma \cdot\left(T_{a}\right)^{4} \cdot\left[a \cdot \ln \left(\frac{e_{a}}{T_{a}}\right)+b \cdot \varphi+c\right],
$$

where $R_{\downarrow}$ is the downward longwave radiation (watts per meter square) under all-sky conditions; $T_{a}$ is the ambient dry-bulb temperature (Kelvin); $e_{a}$ is the water vapor pressure (hectopascal); $\varphi$ is the relative humidity (percentage); $\sigma$ is the Stefan-Boltzmann constant, 5.67 $\times 10^{-8}\left(\mathrm{~W} \mathrm{~m}^{-2} \mathrm{~K}^{-4}\right) ; a, b$, and $c$ are the empirical coefficients.

Clouds can increase the LW radiation up to $34 \%$ with a $100 \%$ cloud cover of low $(<2 \mathrm{~km})$ clouds, ${ }^{4}$ and therefore, it should be

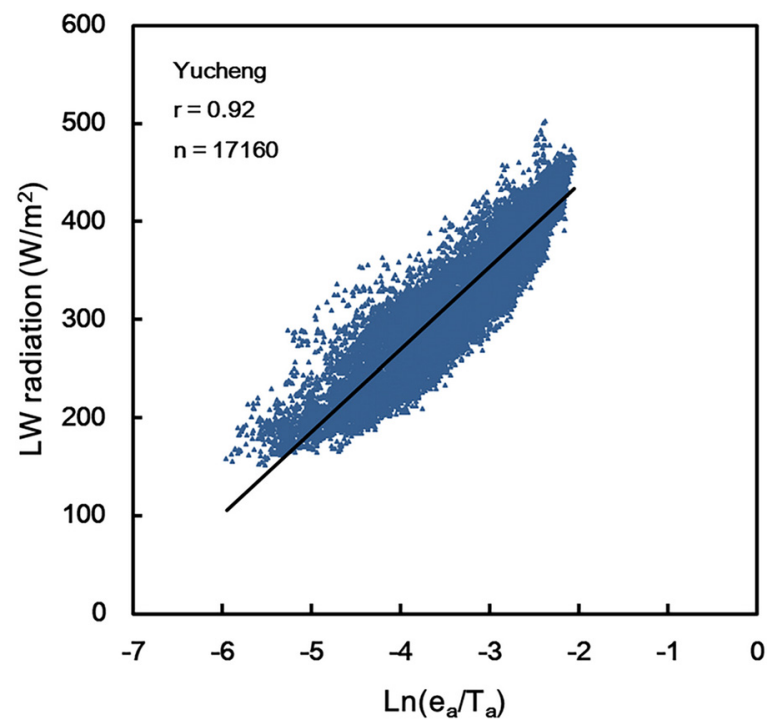

FIG. 2. Correlation between LW radiation and $\ln \left(e_{a} / T_{a}\right)$, Yucheng, 2003-2004. $n$ is the sampling number. considered in the LW radiation model. Crawford and Duchon ${ }^{18}$ proposed an LW radiation model for all-sky conditions with a cloud fraction instead of the cloud cover data, where the cloud fraction [in Eq. (2)] was defined as the ratio of the measured solar radiation to the clear-sky radiation.

In this study, the cloud cover data in the four locations of China were unavailable, while the global solar radiation was measured in the daytime. The clearness index, which is defined as the ratio of the measured solar radiation to the extraterrestrial solar radiation [Eq. (4)], can be regarded as an indicator of cloud cover. $^{23}$ Therefore, for the daytime, another LW radiation model [Eq. (6)] was proposed with a cloud modification factor based on the clearness index,

$$
\begin{aligned}
& c l f^{\prime}=1-S, \\
& c l f=1-K_{t},
\end{aligned}
$$

where $c l f^{\prime}$ is the cloud fraction in the Crawford and Duchon model; clf is the cloud modification factor in this study; $S$ is the ratio of the measured solar radiation to the clear-sky radiation, the detailed formula of which can be seen in the Appendix; $K_{t}$ is the clearness index.

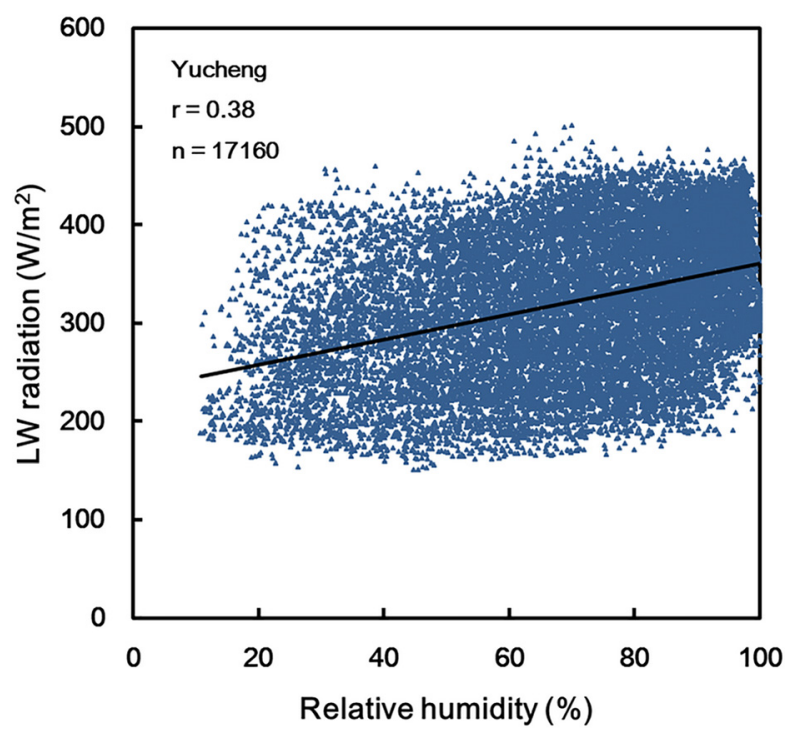

FIG. 3. Correlation between LW radiation and the relative humidity, Yucheng, 2003-2004. $n$ is the sampling number. 
The clearness index can be calculated as follows:

$$
\begin{gathered}
K_{t}=\frac{H_{m}}{H_{0}}, \\
H_{0}=\frac{12 \cdot 3600}{\pi} \cdot G_{s c} \cdot\left(1+0.033 \cos \frac{360 n}{365}\right) \\
\cdot\left[\cos L \cdot \cos \delta \cdot\left(\sin \omega_{2}-\sin \omega_{1}\right)+\frac{\pi\left(\omega_{2}-\omega_{1}\right)}{180} \cdot \sin L \cdot \sin \delta\right],
\end{gathered}
$$

where $H_{m}$ is the hourly measured solar radiation (watts per meter square); $H_{0}$ is the hourly extraterrestrial solar radiation (watts per meter square); ${ }^{24} G_{s c}$ is the solar constant, $1367 \mathrm{~W} / \mathrm{m}^{2} ; n$ is the Julian day of the year; $L$ is the local latitude (degree); $\delta$ is the declination angle (degree); $\omega_{1}$ and $\omega_{2}$ are the hour angle at the beginning and end of the time interval (degree).

The proposed model with the cloud modification factor for the daytime is expressed as follows:

$$
R_{\downarrow}=\sigma \cdot\left(T_{a}\right)^{4} \cdot\left[c l f+(1-c l f) \cdot\left(a \cdot \ln \left(\frac{e_{a}}{T_{a}}\right)+b \cdot \varphi+c\right)\right],
$$

where $c l f$ is the cloud modification factor in Eq. (3).

\section{Existing LW radiation models}

Two existing LW radiation models developed for all-sky conditions were selected to compare with our proposed models.

\section{Sridhar model}

Brutsaert ${ }^{17}$ proposed a model based on the water vapor pressure and ambient temperature for the clear-sky condition, and Sridhar and Elliott $^{25}$ then calibrated the Brutsaert model for four locations representing different geographical and climatological conditions. Therefore, the Sridhar model can be used for all-sky conditions (clear and cloudy) [Eq. (7)], which was compared with our proposed model for the all day in this study,

$$
R_{\downarrow}=\sigma \cdot\left(T_{a}\right)^{4} \cdot\left[1.31 \cdot\left(\frac{e_{a}}{T_{a}}\right)^{\frac{1}{7}}\right] .
$$

\section{Crawford and Duchon model}

As mentioned above, the Crawford and Duchon model was used for all-sky conditions with consideration of the cloud fraction, which can be expressed by

$$
\begin{aligned}
R_{\downarrow}= & \sigma \cdot\left(T_{a}\right)^{4} \cdot\left\{c l f^{\prime}+\left(1-c l f^{\prime}\right)\right. \\
& \left.\cdot\left(1.22+0.06 \cdot \sin \left[(\text { month }+2) \cdot\left(\frac{\pi}{6}\right)\right]\right) \cdot\left(\frac{e_{a}}{T_{a}}\right)^{\frac{1}{7}}\right\},
\end{aligned}
$$

where month is the number of months in a year; $c l f^{\prime}$ is the cloud fraction in Eq. (2).

\section{Assessment metrics}

The values of $\mathrm{R}^{2}$ and root mean square error (RMSE) were used to evaluate the accuracy of the proposed and existing LW radiation models. These indicators can be calculated as follows:

$$
\begin{gathered}
R^{2}=1-\frac{\sum_{i=1}^{n}\left(L W_{i, m}-L W_{i, c}\right)^{2}}{\sum_{i=1}^{n}\left(L W_{i, m}-L W_{m, a v g}\right)^{2}}, \\
\text { RMSE }=\sqrt{\frac{1}{n} \sum_{i=1}^{n}\left(L W_{i, m}-L W_{i, c}\right)^{2}},
\end{gathered}
$$

where $R^{2}$ is the coefficient of determination; RMSE is the root mean square error; $L W_{i, m}$ and $L W_{i, c}$ are the $i$ th measured and estimated values, respectively (watts per meter square); $L W_{m, a v g}$ is the average of the measured values (watts per meter square); $n$ is the total number of measurements.

\section{E. Radiative cooling potential}

Radiative cooling is a thermal process, the heat from which is transferred from a high-temperature object to a low-temperature one through emitting longwave radiation. For the buildings, the radiative cooling is a kind of passive cooling technique which uses the radiative heat transfer effect to cool the building facing a colder atmosphere. ${ }^{2}$ The building envelope can be cooled by radiative heat transfer especially during the nighttime since it can obtain more heat from solar radiation during the daytime. Radiative cooling can reduce the energy consumption for building cooling in summer; therefore, it is necessary to calculate the radiative cooling potential of different locations in summer.

In this study, the radiative cooling potential of the ground surface was defined as the difference between the longwave radiation emitted by the ground surface and the atmospheric downward longwave radiation [Eq. (11)]..$^{20}$ Assuming that the ground surface temperature $\left(\mathrm{T}_{\mathrm{s}}\right)$ in Eq. (12) is equal to the ambient temperature $\left(\mathrm{T}_{\mathrm{a}}\right)$ for simplicity $\left(\mathrm{T}_{\mathrm{s}}=\mathrm{T}_{\mathrm{a}}\right)$, then the radiative cooling potential can be calculated as follows:

$$
\begin{gathered}
R_{\text {cooling }}=R_{\uparrow}-R_{\downarrow}, \\
R_{\uparrow}=\sigma \cdot\left(T_{s}\right)^{4},
\end{gathered}
$$

where $R_{\text {cooling }}$ is the radiative cooling potential (watts per meter square); $R_{\uparrow}$ is the ground surface longwave radiation (watts per meter square); $R_{\downarrow}$ is the LW downward radiation (watts per meter square); $T_{s}$ is the ground surface temperature (Kelvin).

\section{RESULTS AND DISCUSSION \\ A. Empirical coefficients}

The empirical coefficients in Eq. (1) were first calculated using the measured LW radiation, the ambient dry-bulb temperature, the water vapor pressure, and the relative humidity based on the regression analysis. Regression analysis was conducted on each of the four locations, respectively, as well as on the whole dataset (All locations) combining the four locations. The empirical coefficients of Eq. (1) for the all day, nighttime, and daytime are shown in Tables II, III, and IV, respectively.

For the daytime, if cloud cover or solar radiation data were unavailable for one location, Eq. (1) can be employed simply with only 
TABLE II. Empirical coefficients in Eq. (1) for the all day.

\begin{tabular}{lccccccc}
\hline \hline No. & Location & $\mathrm{a}$ & $\mathrm{b}$ & $\mathrm{c}$ & $\mathrm{r}$ & $\mathrm{RMSE}\left(\mathrm{W} / \mathrm{m}^{2}\right)$ & $\mathrm{n}^{\mathrm{a}}$ \\
\hline 1 & Changbaishan & 0.080 & 0.0013 & 1.037 & 0.92 & 30.28 & 14040 \\
2 & Haibei & 0.101 & 0.0026 & 1.036 & 0.88 & 32.10 & 8688 \\
3 & Qinghai & 0.080 & 0.0015 & 1.032 & 0.89 & 27.88 & 15216 \\
4 & Yucheng & 0.080 & 0.0011 & 1.022 & 0.92 & 28.12 & 17160 \\
5 & All locations & 0.080 & 0.0011 & 1.029 & 0.92 & 31.54 & 55104 \\
\hline \hline
\end{tabular}

${ }^{a}$ n: Sampling number.

TABLE III. Empirical coefficients in Eq. (1) for the nighttime.

\begin{tabular}{lcccccccc}
\hline \hline No. & Location & a & b & $c$ & r & $\operatorname{RMSE}\left(W / m^{2}\right)$ & $\mathrm{n}^{\mathrm{a}}$ \\
\hline 1 & Changbaishan & 0.080 & 0.0013 & 1.030 & 0.91 & 30.68 & 7046 \\
2 & Haibei & 0.100 & 0.0027 & 1.025 & 0.89 & 30.13 & 4600 \\
3 & Qinghai & 0.074 & 0.0017 & 1.017 & 0.92 & 24.10 & 7538 \\
4 & Yucheng & 0.087 & 0.0012 & 1.037 & 0.92 & 28.34 & 8574 \\
5 & All locations & 0.080 & 0.0014 & 1.026 & 0.92 & 29.87 & 27758 \\
\hline \hline
\end{tabular}

${ }^{a}$ n: Sampling number.

TABLE IV. Empirical coefficients in Eq. (1) for the daytime.

\begin{tabular}{lccccccc}
\hline \hline No. & Location & $\mathrm{a}$ & $\mathrm{b}$ & $\mathrm{c}$ & $\mathrm{r}$ & $\operatorname{RMSE}\left(\mathrm{W} / \mathrm{m}^{2}\right)$ & $\mathrm{n}^{\mathrm{a}}$ \\
\hline 1 & Changbaishan & 0.045 & 0.0025 & 0.837 & 0.93 & 27.68 & 6994 \\
2 & Haibei & 0.052 & 0.0038 & 0.762 & 0.86 & 32.50 & 4088 \\
3 & Qinghai & 0.037 & 0.0029 & 0.778 & 0.87 & 28.12 & 7678 \\
4 & Yucheng & 0.093 & 0.0012 & 1.054 & 0.93 & 28.25 & 8586 \\
5 & All locations & 0.086 & 0.0014 & 1.044 & 0.92 & 31.26 & 27346 \\
\hline \hline
\end{tabular}

${ }^{a}$ : Sampling number.

routine meteorological parameters. To further explore the effects of clouds on LW radiation, Eq. (6) was proposed with a cloud fraction parameter subsequently. The empirical coefficients of Eq. (6) are shown in Table $V$.

The empirical coefficients of the four locations had a little difference with each other, in order to obtain more general LW radiation models for applying at different locations of China; they were also

TABLE V. Empirical coefficients in Eq. (6) for the daytime with the cloud modification factor.

\begin{tabular}{lccccccc}
\hline \hline No. & Location & a & b & c & r & RMSE $\left(W / m^{2}\right)$ & $\mathrm{n}^{\mathrm{a}}$ \\
\hline 1 & Changbaishan & 0.074 & 0.0008 & 0.858 & 0.95 & 23.59 & 6994 \\
2 & Haibei & 0.111 & 0.0003 & 1.021 & 0.85 & 33.99 & 4088 \\
3 & Qinghai & 0.103 & 0.0004 & 1.035 & 0.91 & 24.35 & 7678 \\
4 & Yucheng & 0.139 & 0.0004 & 1.045 & 0.93 & 26.56 & 8586 \\
5 & All locations & 0.118 & 0 & 1.033 & 0.93 & 28.67 & 27346 \\
\hline \hline
\end{tabular}

${ }^{a} \mathrm{n}$ : Sampling number. calculated using the whole dataset (All locations) combining the four locations. It can be seen that the correlation coefficients ( $r$ ) of the whole dataset (All locations) were all very good in Tables II-V. The correlation between the measured and estimated hourly LW radiation for the whole dataset is also shown in Fig. 4.

Comparing the empirical coefficients in Tables IV and V, it was worthy to notice that the values of $b$ were very small in Table $V$, even became zero for the whole dataset (All locations). It may be due to the fact that the relative humidity can indirectly represent the effect of clouds on LW radiation. The relative humidity had a correlation with the cloud modification factor as shown in Fig. 5 in this study; however, the accurate relationship between the relative humidity and the cloud cover needs further investigation.

Based on the above discussion, the proposed models for four cases in this study are shown in Table VI, which were validated using the measured LW radiation (shown in Table I) subsequently.

\section{B. Model validation}

The model validation was first conducted on each of the four locations, respectively, and then on the whole dataset (All locations) combining the four locations. The determination coefficient $\left(\mathrm{R}^{2}\right)$ and the root mean square error (RMSE) are shown for the four cases in Tables VII, VIII, and IX.

For the all day, the performance of the proposed model [Eq. (13)] had a little difference, among which Yucheng showed the best performance with the largest $\mathrm{R}^{2}$ and smallest RMSE, while the All locations also had very good performance with an $\mathrm{R}^{2}$ value of 0.86 and an RMSE of $30.26 \mathrm{~W} / \mathrm{m}^{2}$, which means that the general proposed model is suitable for application in China.

For the nighttime, the performance of Eq. (16) was very good, where the RMSE of both Haibei and Qinghai was smaller than that in Table VII. The radiative cooling usually operates during the nighttime since the solar radiation existed in the daytime, and therefore, Eq. (16) was recommended to apply in calculating the radiative cooling potential for locations in China.

For the daytime, it can be seen that the performance of the proposed model was improved in Changbaishan and Haibei by adding the cloud modification factor, and Eq. (15) performed better than Eq. (14) with an $\mathrm{R}^{2}$ value of 0.87 and an RMSE of $28.59 \mathrm{~W} / \mathrm{m}^{2}$ for the whole dataset. Therefore, Eq. (15) is more favorable than Eq. (14) if the cloud data or cloud modification factor was available. Otherwise, Eq. (14) was also acceptable to be applied with routine meteorological parameters only.

\section{Comparison with the existing models}

In order to better discuss the performance of the proposed LW radiation model, the proposed models were compared with some previous models. Since the existing models used for all-sky conditions were fewer compared to those for clear-sky conditions, two existing models for all-sky conditions were selected for comparison using the validation dataset (shown in Table I) in this study.

For the all day, both the proposed model [Eq. (13)] and the Sridhar model [Eq. (7)] were using the whole dataset (All locations) combining the four locations, and the comparison results are shown in Fig. 6. The results showed that the proposed model performed much better than the Sridhar one with the RMSE being reduced by $17.73 \%$. 


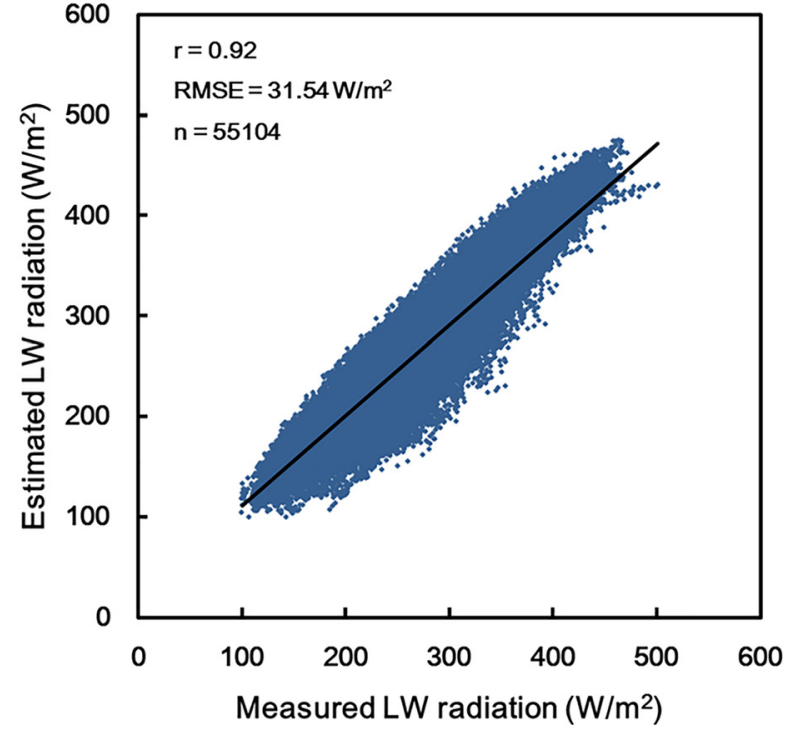

(a)

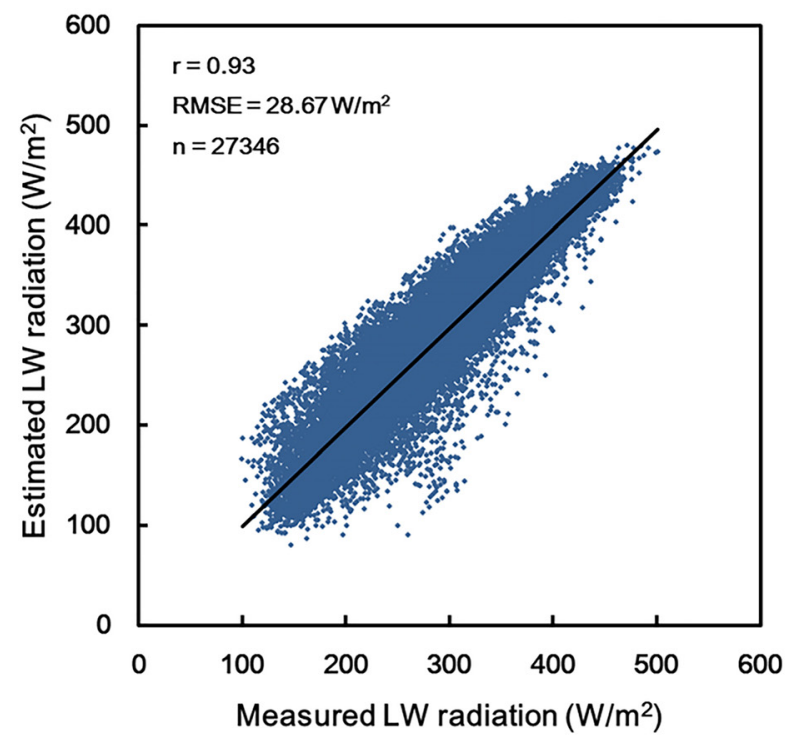

(c)

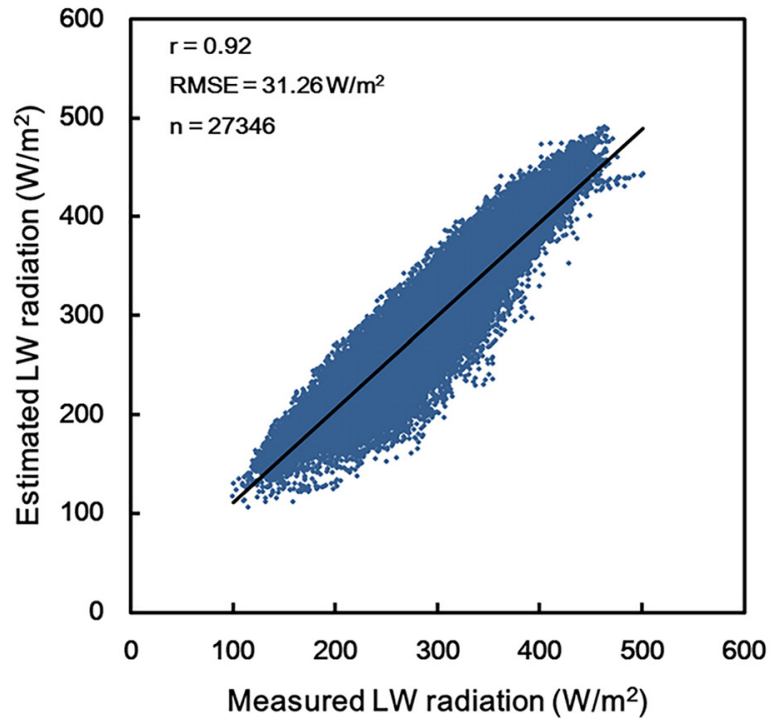

(b)

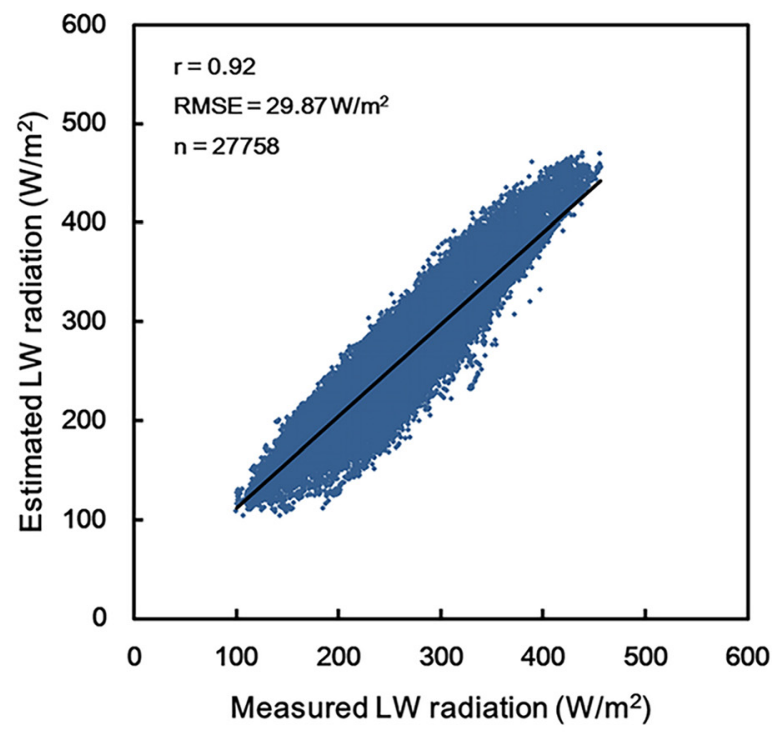

(d)

FIG. 4. Correlation between measured and estimated hourly LW radiation using the whole dataset for four cases. $n$ is the sampling number. (a) All day, (b) daytime, (c) daytime with the cloud modification factor, and (d) nighttime.

Although the Sridhar model was proposed with different geographical and climatological conditions, the newly proposed model [Eq. (13)] was more suitable for China.

For the daytime, the proposed model [Eq. (15)] and the Crawford and Duchon model [Eq. (8)] were compared based on the whole dataset (All locations) combining the four locations. The new proposed model has better performance than the Crawford and Duchon one with smaller RMSE (shown in Fig. 7). Therefore, it was recommended to employ for the daytime in China.

\section{Distribution of $\mathrm{LW}$ radiation and radiative cooling potential}

The hourly LW radiation was required for building energy simulation, and the calculation of LW radiation exchange between the building surface and the atmosphere was also necessary for building radiative cooling design. Zhang and Yang $^{21}$ developed the typical meteorological year (TMY) for 360 locations in China for building simulation. The TMY dataset can represent the long-term typical 


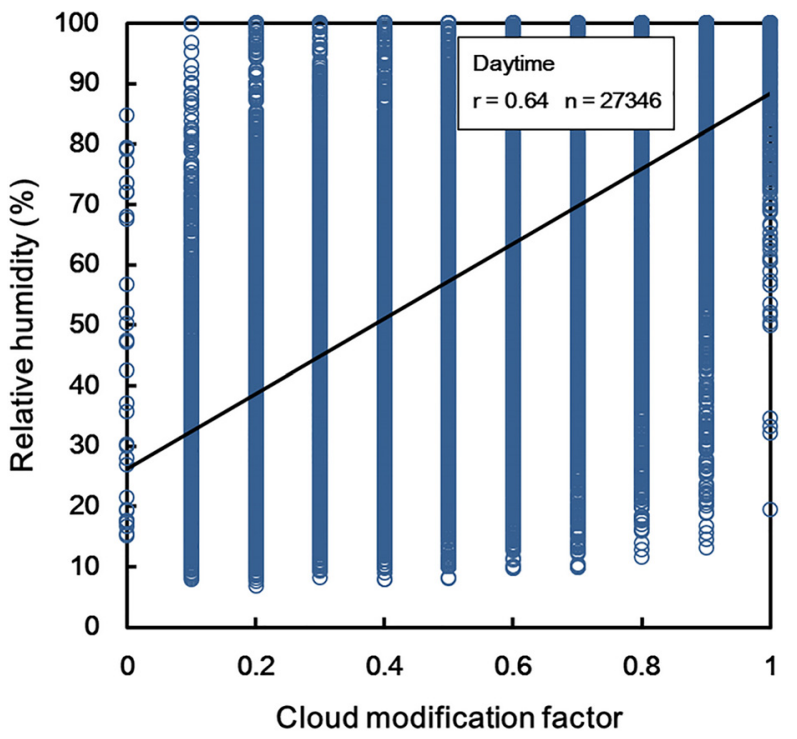

FIG. 5. Correlation between the cloud modification factor and the relative humidity during daytime periods for the whole dataset. $\mathrm{n}$ is the sampling number.

weather conditions over a year for one location, however, which was lacking hourly LW radiation data. Therefore, the hourly LW radiation was calculated using Eq. (13) for 351 locations in China based on the TMY dataset, which can be a valuable supplement to TMY.

Building envelops can be cooled by effective radiation especially during the nighttime since solar radiation was significantly stronger than LW radiation during the daytime. Recently, it was demonstrated that the new glass-polymer hybrid metamaterials have a high reflectance in the solar spectrum and high emittance in the longwave spectrum for the daytime; ${ }^{26}$ however, further research is also needed for building radiative cooling during the daytime. In most regions of China, the hottest month is July; therefore, the hourly average of
TABLE VII. Validation results of the proposed model [Eq. (13)] for the all day.

\begin{tabular}{lcccc}
\hline \hline No. & Location & $\mathrm{R}^{2}$ & $\operatorname{RMSE}\left(\mathrm{W} / \mathrm{m}^{2}\right)$ & $\mathrm{n}^{\mathrm{a}}$ \\
\hline 1 & Changbaishan & 0.86 & 31.33 & 7320 \\
2 & Haibei & 0.77 & 35.04 & 4968 \\
3 & Qinghai & 0.76 & 30.52 & 8352 \\
4 & Yucheng & 0.90 & 25.39 & 7968 \\
5 & All locations & 0.86 & 30.26 & 28608 \\
\hline \hline
\end{tabular}

${ }^{a}$ : Sampling number.

TABLE VIII. Validation results of the proposed model [Eq. (16)] for the nighttime.

\begin{tabular}{lcccc}
\hline \hline No. & Location & $\mathrm{R}^{2}$ & $\mathrm{RMSE}\left(\mathrm{W} / \mathrm{m}^{2}\right)$ & $\mathrm{n}^{\mathrm{a}}$ \\
\hline 1 & Changbaishan & 0.86 & 31.04 & 3648 \\
2 & Haibei & 0.83 & 30.20 & 2743 \\
3 & Qinghai & 0.82 & 25.86 & 4157 \\
4 & Yucheng & 0.87 & 27.82 & 4005 \\
5 & All locations & 0.87 & 28.59 & 14553 \\
\hline \hline
\end{tabular}

${ }^{\mathrm{a}} \mathrm{n}$ : Sampling number.

TABLE IX. Validation results of the proposed models [Eqs. (14) and (15)] for the daytime. a: Equation (14). b: Equation (15). n: Sampling number.

\begin{tabular}{lcccccc}
\hline \hline No. & Location & $\mathrm{R}^{2}-\mathrm{a}$ & $\begin{array}{c}\text { RMSE-a } \\
\left(\mathrm{W} / \mathrm{m}^{2}\right)\end{array}$ & $\mathrm{R}^{2}-\mathrm{b}$ & $\begin{array}{c}\text { RMSE-b } \\
\left(\mathrm{W} / \mathrm{m}^{2}\right)\end{array}$ & $\mathrm{n}$ \\
\hline 1 & Changbaishan & 0.87 & 30.09 & 0.90 & 26.14 & 3672 \\
2 & Haibei & 0.75 & 35.50 & 0.80 & 31.59 & 2225 \\
3 & Qinghai & 0.75 & 29.24 & 0.75 & 29.13 & 4195 \\
4 & Yucheng & 0.87 & 28.38 & 0.87 & 28.41 & 3963 \\
5 & All locations & 0.85 & 30.30 & 0.87 & 28.59 & 14055 \\
\hline \hline
\end{tabular}

TABLE VI. LW radiation models for the all day, daytime, and nighttime.

\begin{tabular}{lc}
\hline \hline Period & Formulation \\
\hline All day & $R_{\downarrow}=\sigma \cdot\left(T_{a}\right)^{4} \cdot\left[0.08 \cdot \ln \left(\frac{e_{a}}{T_{a}}\right)+0.0011 \cdot \varphi+1.029\right]$ \\
& $R_{\downarrow}=\sigma \cdot\left(T_{a}\right)^{4} \cdot\left[0.086 \cdot \ln \left(\frac{e_{a}}{T_{a}}\right)+0.0014 \cdot \varphi+1.044\right]$ \\
Daytime & $R_{\downarrow}=\sigma \cdot\left(T_{a}\right)^{4} \cdot\left[c l f+(1-c l f) \cdot\left(0.118 \cdot \ln \left(\frac{e_{a}}{T_{a}}\right)+1.033\right)\right]$ \\
Daytime with the cloud modification factor & \\
& $R_{\downarrow}=\sigma \cdot\left(T_{a}\right)^{4} \cdot\left[0.08 \cdot \ln \left(\frac{e_{a}}{T_{a}}\right)+0.0014 \cdot \varphi+1.026\right]$
\end{tabular}




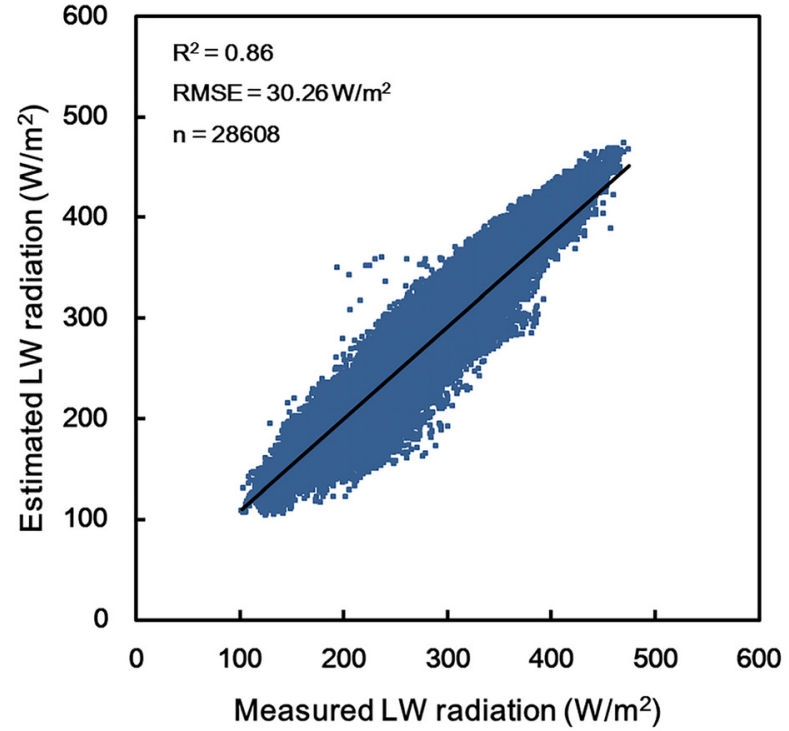

(a)

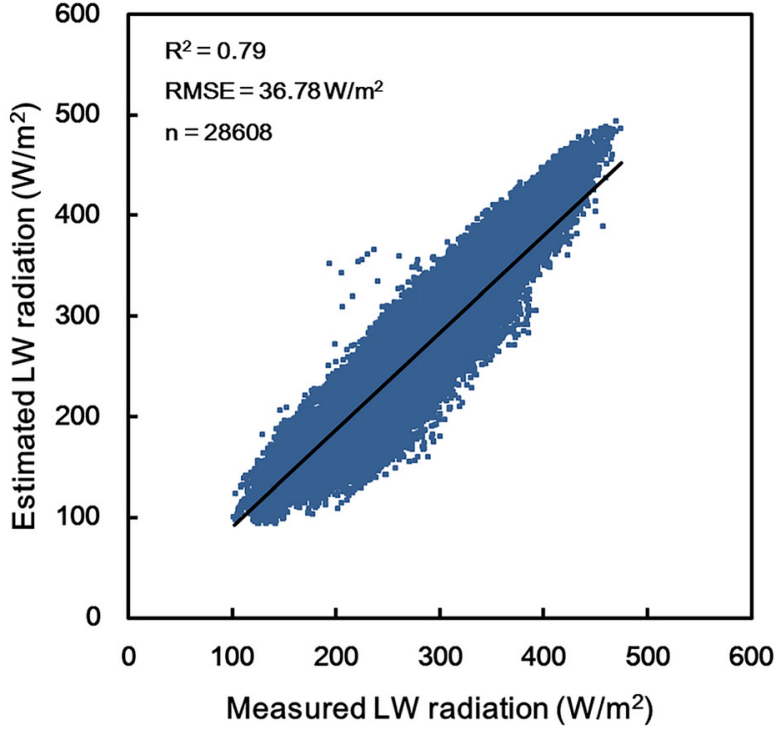

(b)

FIG. 6. Estimated LW radiation with respect to the measured LW radiation for the all day. $n$ is the sampling number. (a) Proposed model [Eq. (13)] and (b) Sridhar model.

radiative cooling potential was calculated in July for the nighttime based on Eqs. (11), (12), and (16).

In order to describe the spatial distribution of LW radiation and radiative cooling potential, ${ }^{27}$ the values for 351 locations were interpolated using the Kriging method in ArcGIS 10.0 software; then, the distribution maps of LW radiation and radiative cooling potential were obtained over China.

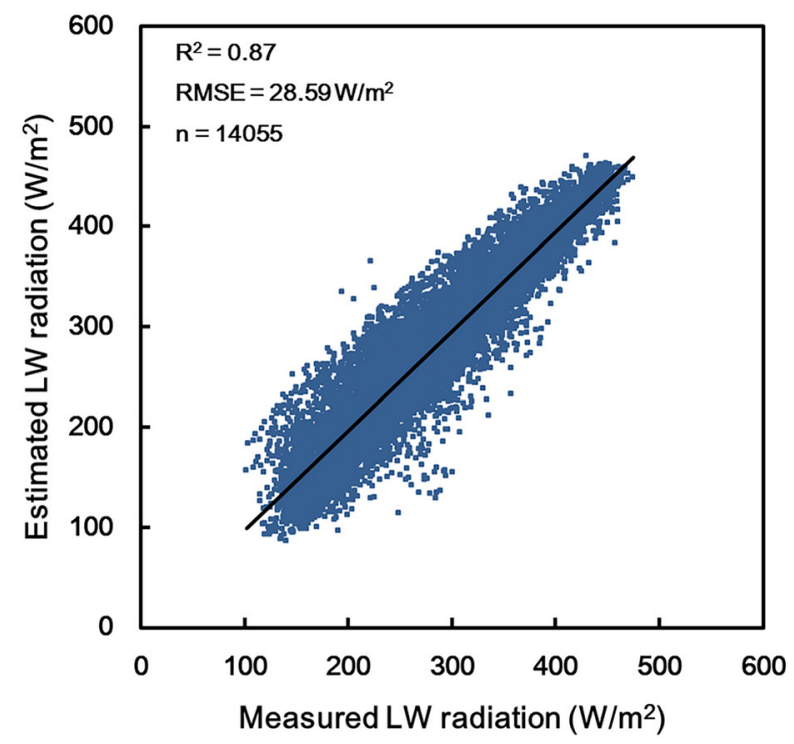

(a)
For the distribution map of LW radiation (shown in Fig. 8), the LW radiation gradually decreases from Southeast to Northwest China excluding the Xinjiang area; it is the smallest in the Tibetan Plateau region. It may be because the temperature in Southeast is higher than that in Northwest in summer, and the Tibetan Plateau region has the lowest temperature with the highest altitude. For the distribution map of radiative cooling potential (shown in Fig. 9), the radiative cooling

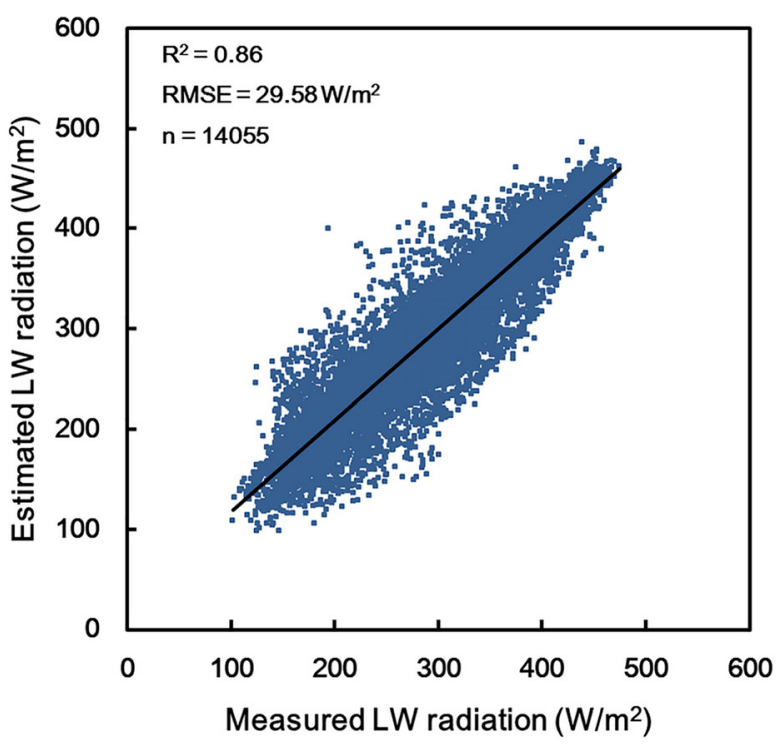

(b)

FIG. 7. Estimated LW radiation with respect to measured LW radiation for the daytime. $n$ is the sampling number. (a) Proposed model [Eq. (15)] and (b) Crawford and Duchon model. 


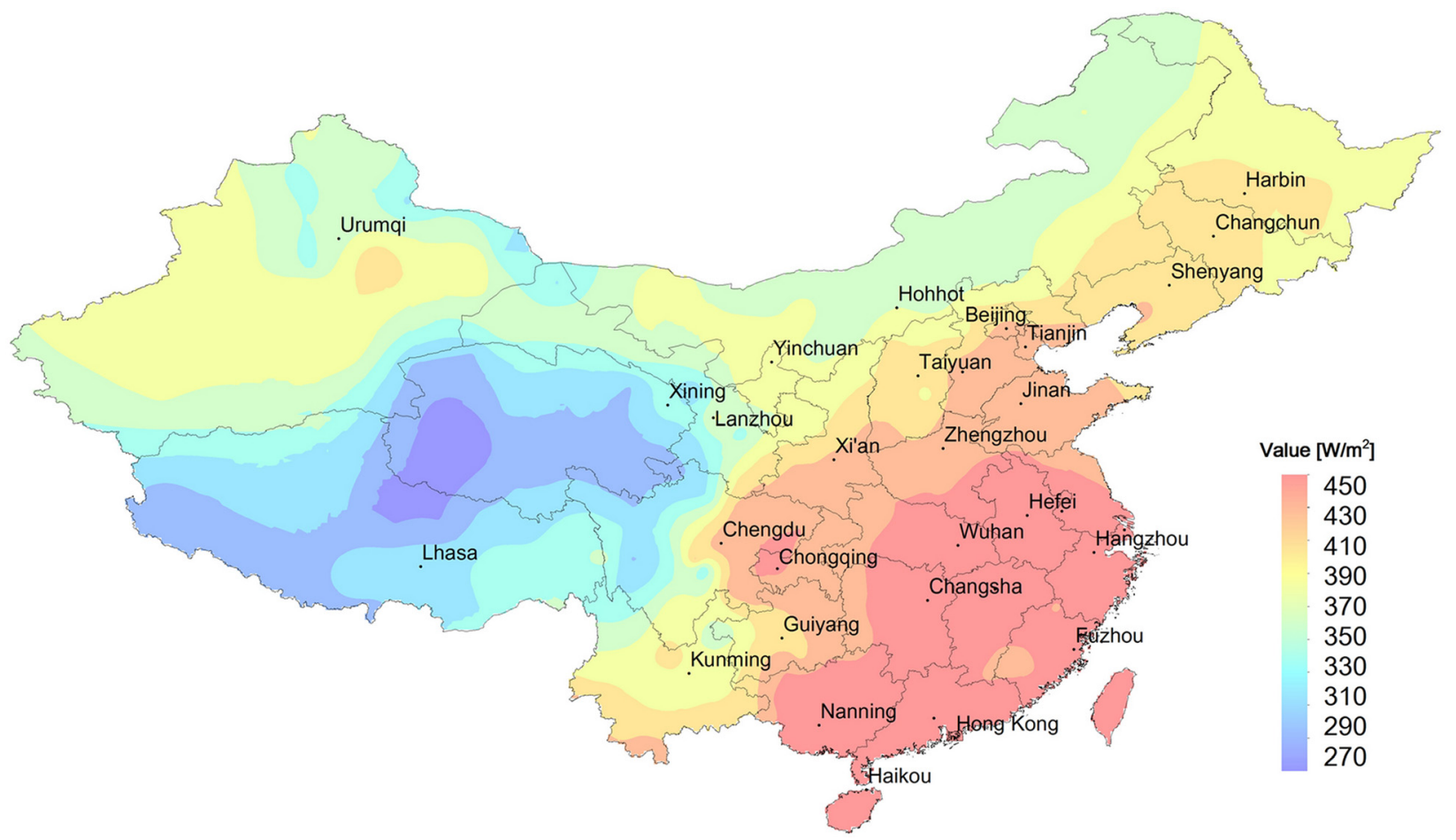

FIG. 8. Distribution map of LW radiation (watts per meter square) over parts of China for the all day in July.

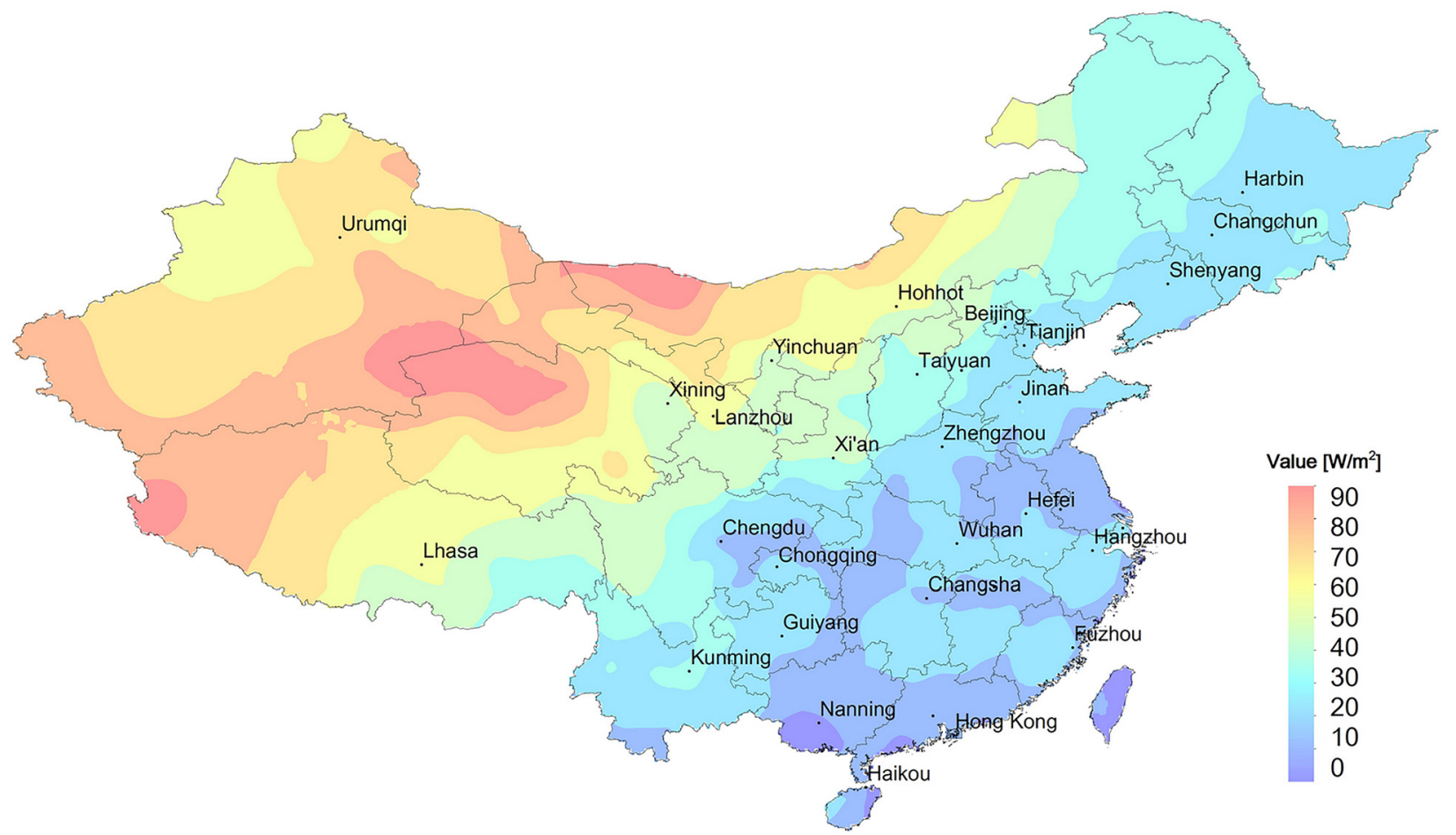

FIG. 9. Distribution map of radiative cooling potential (watts per meter square) over parts of China for the nighttime in July. 
potential is large in Northwest, while it is small in Southeast. It is wellunderstood that the LW radiation is strongly related to the absolute water vapor content in the atmosphere, and so it is larger for more humid conditions. Based on Eq. (11), the radiative cooling potential will be smaller for more humid conditions such as Southeast China.

\section{E. Applicable range of the proposed models}

As shown in Table I, the longitude ranges of the four observation locations were $101.2^{\circ} \mathrm{E}-128.1^{\circ} \mathrm{E}$, while the latitude ranges of that were $36.5^{\circ} \mathrm{N}-41.4^{\circ} \mathrm{N}$, and there is no observation station for South China in this study. Therefore, the adaptability of the proposed models to the geographic and meteorological conditions in South China needs further verification. Moreover, further investigation is also needed to apply the proposed models and the LW radiation dataset in the building simulation and the design of the building radiative cooling system.

\section{CONCLUSIONS}

In this study, new hourly LW radiation models were proposed under all-sky conditions with the measured LW radiation dataset in four locations (Changbaishan, Haibei, Qinghai, and Yucheng) of China. The new hourly LW radiation models (shown in Table VI) can be classified into four cases: All day, nighttime, and daytimes with and without the cloud modification factor. The main conclusions of this study are as follows:

1. For the all day, the proposed LW radiation [Eq. (13)] performs well with an $\mathrm{R}^{2}$ value of 0.86 and an RMSE of $30.26 \mathrm{~W} / \mathrm{m}^{2}$, which is more accurate than the Sridhar model under all-sky conditions for locations in China.

2. For the daytime, if the hourly cloud data or the solar radiation data are available, the model with the cloud modification factor [Eq. (15)] is favorable, which is more accurate than the Crawford and Duchon model with an $\mathrm{R}^{2}$ value of 0.87 and an RMSE of $28.59 \mathrm{~W} / \mathrm{m}^{2}$; otherwise, Eq. (14) is recommended for simplicity with limited errors.

3. For the nighttime, the proposed model [Eq. (16)] was employed in calculating the radiative cooling potential of 351 locations in China, which can provide a valuable reference for the design of building a radiative cooling system.

4. The hourly LW radiation dataset of 351 locations in China was developed using Eq. (13), which can be a valuable supplement to the typical meteorological year (TMY).

\section{ACKNOWLEDGMENTS}

We are deeply grateful to the AsiaFlux for supplying the measured LW radiation and other meteorological parameters in this study.

\section{APPENDIX: THE INEICHEN CLEAR-SKY SOLAR MODEL}

The Ineichen clear-sky global solar radiation in Eq. (2) can be expressed as s $^{3,28-31}$

$$
H_{c}=c_{1} \cdot I_{0} \cdot \sin (h) \cdot e^{0.01 \cdot A M^{1.8}-c_{2} \cdot A M \cdot\left(f_{1}+f_{2} \cdot\left(T_{L}-1\right)\right),}
$$

where $H_{c}$ is the clear-sky solar radiation (watts per meter square); $c_{1}, c_{2}, f_{1}$, and $f_{2}$ are the altitude correction coefficients; $I_{0}$ is the extraterrestrial irradiance (watts per meter square); $h$ is the solar altitude angle (degree); $A M$ is the air mass; $T_{L}$ is the Linke turbidity factor.

The altitude correction coefficients are

$$
\begin{gathered}
C_{1}=5.09 \times 10^{-5} \cdot A l t+0.868 \\
C_{2}=3.92 \times 10^{-5} \cdot A l t+0.0387 \\
f_{1}=e^{-A l t / 8000} \\
f_{2}=e^{-A l t / 1250}
\end{gathered}
$$

where Alt is the altitude (meter).

The extraterrestrial irradiance $I_{0}$ is expressed as

$$
I_{0}=1367 *\left(1+0.033 \cos \left(\frac{2 \pi}{365} \cdot D O Y\right)\right),
$$

where $D O Y$ is the Julian day of the year.

The air mass $A M$ is expressed as a function of solar altitude angle,

$$
\mathrm{AM}=\frac{1}{\sin (h)+0.50572 *(h+6.07995)^{-1.6364}} .
$$

The Linke turbidity factor $T_{L}$ is extracted from monthly Link turbidity images. $^{32}$

\section{REFERENCES}

${ }^{7}$ M. G. Iziomon, G. Moses, H. E. L. M. U. T. Mayer, and A. N. D. R. E. A. S. Matzarakis, "Downward atmospheric longwave irradiance under clear and cloudy skies: Measurement and parameterization," J. Atmos. Sol.-Terr. Phys. 65(10), 1107-1116 (2003).

${ }^{2}$ S. Vall and A. Castell, "Radiative cooling as low-grade energy source: A literature review,” Renewable Sustainable Energy Rev. 77, 803-820 (2017).

${ }^{3} \mathrm{M}$. Li, Y. Jiang, and C. F. Coimbra, "On the determination of downward longwave irradiance under all-sky conditions,” Sol. Energy 144, 40-48 (2017).

${ }^{4}$ M. A. Goforth, G. W. Gilchrist, and J. D. Sirianni, "Cloud effects on thermal downwelling sky radiance," Proc. SPIE 4710, 203-213 (2002).

${ }^{5} \mathrm{~K}$. Wang and R. E. Dickinson, "Global atmospheric downward longwave radiation at the surface from ground-based observations, satellite retrievals, and reanalyses," Rev. Geophys. 51(2), 150-185, https://doi.org/10.1002/rog.20009 (2013).

${ }^{6}$ L. Evangelisti, C. Guattari, and F. Asdrubali, "On the sky temperature models and their influence on buildings energy performance: A critical review," Energy Build. 183, 607-625 (2019).

${ }^{7}$ F. X. Kneizys et al., Users guide to LOWTRAN 7. No. AFGL-TR-88-0177. Air Force Geophysics Lab Hanscom AFB MA, 1988.

${ }^{8}$ H. E. Snell et al., "Validation of FASE (FASCODE for the environment) and MODTRAN3: Updates and comparisons with clear-sky measurements," Proc. SPIE 2578, 194-204 (1995).

${ }^{9}$ I. Masiri et al., "A technique for mapping downward longwave radiation using satellite and ground-based data in the tropics," Renewable Energy 103, 171-179 (2017).

${ }^{10} \mathrm{D}$. Brunt, "Notes on radiation in the atmosphere. I," Quart. J. R. Meteorol. Soc. 58(247), 389-420 (1932).

${ }^{11}$ W. M. Elsasser, "Heat transfer by infrared radiation in the atmosphere," Harv. Meteor. Stud. 6, 107 (1942).

${ }^{12}$ W. C. Swinbank, "Long-wave radiation from clear skies," Quart. J. R. Meteorol. Soc. 89(381), 339-348 (1963).

${ }^{13}$ S. B. Idso and R. D. Jackson, "Thermal radiation from the atmosphere," J. Geophys. Res. 74(23), 5397-5403, https://doi.org/10.1029/JC074i023p05397 (1969).

${ }^{14} \mathrm{~S}$. B. Idso, "A set of equations for full spectrum and 8-to $14-\mu \mathrm{m}$ and 10.5 -to $12.5-\mu \mathrm{m}$ thermal radiation from cloudless skies," Water Resour. Res. 17(2), 295-304, https://doi.org/10.1029/WR017i002p00295 (1981). 
${ }^{15} \mathrm{M}$. Centeno, "New formulae for the equivalent night sky emissivity," Sol. Energy 28(6), 489-498 (1982).

${ }^{16}$ P. Berdahl and R. Fromberg, "The thermal radiance of clear skies," Sol. Energy 29(4), 299-314 (1982).

${ }^{17} \mathrm{~W}$. Brutsaert, "On a derivable formula for long-wave radiation from clear skies,” Water Resour. Res. 11(5), 742-744, https://doi.org/10.1029/ WR011i005p00742 (1975).

${ }^{18}$ T. M. Crawford and C. E. Duchon, "An improved parameterization for estimating effective atmospheric emissivity for use in calculating daytime downwelling longwave radiation," J. Appl. Meteorol. 38(4), 474-480 (1999).

${ }^{19} \mathrm{~J}$. Wang et al., "Estimation of surface longwave radiation over the Tibetan plateau region using MODIS data for cloud-free skies," IEEE J. Sel. Top. Appl. Earth Obs. Remote Sens. 7(9), 3695-3703 (2014).

${ }^{20} \mathrm{Q}$. Zhang and $\mathrm{L}$. Yu, "Potentials of passive cooling for passive design of residential buildings in China," Energy Procedia 57, 1726-1732 (2014).

${ }^{21} \mathrm{Q}$. Zhang and H. Yang, Typical Meteorological Database Handbook for Buildings (China Building Industry Press, Beijing, China, 2012).

${ }^{22}$ See https://db.cger.nies.go.jp/asiafluxdb/?page_id=15.

${ }^{23} \mathrm{R}$. Kumar and L. Umanand, "Estimation of global radiation using clearness index model for sizing photovoltaic system," Renewable Energy 30(15), 2221-2233 (2005).
${ }^{24}$ J. A. Duffie, W. A. Beckman, and W. M. Worek, Solar Engineering of Thermal Processes (Wiley, New York, 2013), Vol. 3.

${ }^{25} \mathrm{~V}$. Sridhar and R. L. Elliott, "On the development of a simple downwelling longwave radiation scheme," Agric. For. Meteorol. 112(3-4), 237-243 (2002).

${ }^{26}$ Y. Zhai et al., "Scalable-manufactured randomized glass-polymer hybrid metamaterial for daytime radiative cooling," Science 355(6329), 1062-1066 (2017).

${ }^{27} \mathrm{M}$. Li, H. B. Peterson, and C. F. Coimbra, "Radiative cooling resource maps for the contiguous United States," J. Renewable Sustainable Energy 11(3), 036501 (2019).

${ }^{28} \mathrm{~F}$. Kasten and A. T. Young, "Revised optical air mass tables and approximation formula," Appl. Opt. 28(22), 4735-4738 (1989).

${ }^{29} \mathrm{P}$. Ineichen and R. Perez, "A new airmass independent formulation for the Linke turbidity coefficient," Sol. Energy 73(3), 151-157 (2002).

${ }^{30} \mathrm{P}$. Ineichen, "Conversion function between the Linke turbidity and the atmospheric water vapor and aerosol content," Sol. Energy 82(11), 1095-1097 (2008).

${ }^{31}$ R. H. Inman, J. G. Edson, and C. F. Coimbra, "Impact of local broadband turbidity estimation on forecasting of clear sky direct normal irradiance," Sol. Energy 117, 125-138 (2015).

${ }^{32}$ See http://www.soda-pro.com/help/general-knowledge/linke-turbidity-factor. 